\title{
Comparison of Flight Characteristics of Two Different Airplanes and Ice Configurations
}

\author{
Christoph Deiler* \\ DLR (German Aerospace Center), Braunschweig, 38108, Germany
}

\section{Introduction}

Airframe icing can have hazardous effects on the aircraft performance characteristics. Moreover, in case of icing aircraft operational limitations must be adapted to stay inside a shrinked, safe flight envelope. Dynamic behavior changes and a possible premature stall increase the need for pilot situational awareness and an adaptation of the aircraft control strategy.

During the last decades, various accidents worldwide have shown the severity of icing-related degradations as well as the pilots' difficulties to cope with corresponding changes in airplane behavior [1-3]. During the flight in icing conditions, ice can accumulate on airframe parts facing the inflow, e.g., wing or stabilizer leading edges, aircraft nose or engine intakes. The main aerodynamic degradation is expected to be caused by wing ice accretions and manifests itself in a reduced stall angle of attack and increased drag. The shape of those accumulations largely depends on atmospheric conditions, aircraft flight condition and geometry, which leads to distinct aerodynamic effects. The general influence of icing on the aircraft aerodynamics is outlined e.g., in [4]. Various studies on these effects for different airfoils and icing cases (e.g., Refs. [4-9]) as well as for ice shapes on certain parts of the aircraft (e.g., Refs. [10,-14]) have been conducted in the past. To obtain a better understanding of these icing effects on aircraft characteristics, new aerodynamic models for nonlinear aircraft simulations have been developed [15] 17], which are based on a different approach than already existing models (e.g., in Refs. [18-[21]). In contrast to the existing models, the newly developed models include a separation of different aircraft surfaces (e.g., left and right wing and horizontal tail) to account for local icing effects. These formulations physically relate local lift and drag changes to altered aircraft dynamics.

This research mainly focuses on the changes of flight performance, aircraft dynamic response and handling qualities under icing influence; especially the new results for aircraft not scientifically investigated for icing conditions are complementary to already published research. With regard to small and medium size transport aircraft during commercial operations the icing related aerodynamic degradation could lead to e.g., a reduction of climb performance [2, 22,-24]. Furthermore, the results of an analysis of altered aircraft dynamics and handling qualities under icing influence are interesting for future pilot training. As a result of the general aircraft degradation an envelope shrinkage to maintain a safe flight as proposed e.g., in Ref. [25], might be necessary. Moreover, the corresponding results could also be used to assess the usability and reliability of existing ice detection methods. There are different model developments to evaluate

\footnotetext{
${ }^{*}$ Research Scientist, Institute of Flight Systems, Lilienthalplatz 7, Braunschweig, 38108, Germany
} 
icing-induced changes of the aircraft characteristics in dynamic flight (e.g., see Refs. [26-32] for further details on such approaches) and icing-induced changes of the flight performance [33, 34].

The work presented herein is based on information about the aircraft characteristics under certain icing influences from different sources. Several simulation models for two distinct fixed-wing aircraft and different icing conditions were used for the analysis. System identification techniques allowed to identify high-quality simulation models from flight test data of a Phenom 300 prototype, which were available through a research cooperation on aircraft icing of Brazilian aircraft manufacturer Embraer and DLR [35]. Moreover, results of CFD calculations for the former DLR research aircraft VFW 614 ATTAS under icing influence lead to further simulation models used for the following evaluation. Even though both aircraft are designed for different purposes and during different decades, the comparison of these aircraft could reveal general effects of icing on the one hand but might also show the differences caused by icing on the other. To the knowledge of the author, no such evaluation or information has been published so far. Furthermore, this work focuses on the effects of ice on aircraft performance and flight dynamics with verified aircraft behavior from system identification and CFD, whereas existing work was related to e.g., icing on the aircraft tail [10, 11], had no direct evaluation of the aircraft dynamics [18] or is based on generic models [21].

\section{Modeling of Icing Effects in Aircraft Flight Simulation}

Complex $\Delta$-models were developed in [16, 17] to account for the icing-induced aerodynamic degradation and its effects on the complete aircraft motion. They also allow to predict asymmetric icing effects due to local ice accretion. Similar to the strip method for simulation of the aircraft reaction due to the impact of inhomogeneous flow fields [36], the $\Delta$-models were formulated to individually describe the degrading influence on the local wing aerodynamics. A detailed description of the $\Delta$-model formulation developed during the system identification based on specific and unique flight data from the Embraer Phenom 300 is given in [17]. The available flight test data to estimate parameters of the $\Delta$-model contain measurements of test flights with two different ice configurations: one configuration includes run-back ice on the wing and the other a wing leading-edge ice shape. In both cases, additional ice shapes where present on other aircraft parts [17]. After identification, the model allows the simulation of the aircraft aerodynamics and dynamic motion. The corresponding simulated overall aircraft lift curves and drag polars for the base aircraft and each ice case (run-back and leading-edge ice) are shown in Fig. 1. Note that information about the aircraft aerodynamics are proprietary and the plots do not contain any numbers.

The information about the icing-induced degradation of the VFW 614 ATTAS was available through CFD results within the SuLaDI (Supercooled Large Droplet Icing) project. For a deeper insight into the CFD calculations made and the complete $\Delta$-model formulation used, the reader is referred to Ref. [16]. Figure 2 contains the lift and drag coefficient curves of the base aircraft (previously identified from flight test data) and the degraded aircraft with the different ice shapes on the wing's and horizontal tail's leading edges. Note that the prediction of the drag increase for small lift 


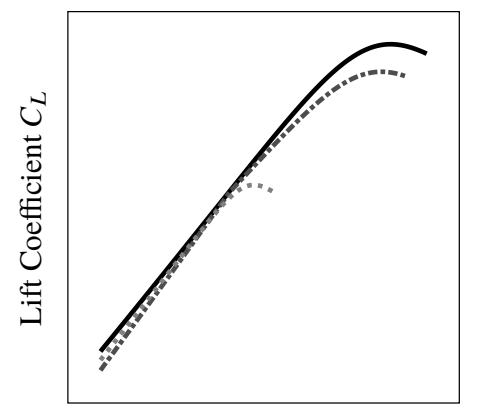

Angle of Attack $\alpha$

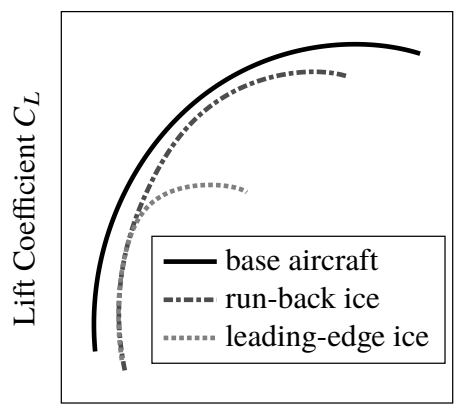

Drag Coefficient $C_{D}$

Fig. 1 Changes of lift and drag curves for different ice cases; aerodynamic model data (after identification) for the Phenom 300; from [17].

coefficients by CFD was much lower than expected. Furthermore, in contrast to the overall aerodynamic degradation given in Fig. 1 for different, independent ice cases, the degradation manifests itself in a continuous manner increasing from base aircraft over the 10 minute ice shapes to the final 20 minute ice shape characteristics in an expectable way (given e.g., in [4]).
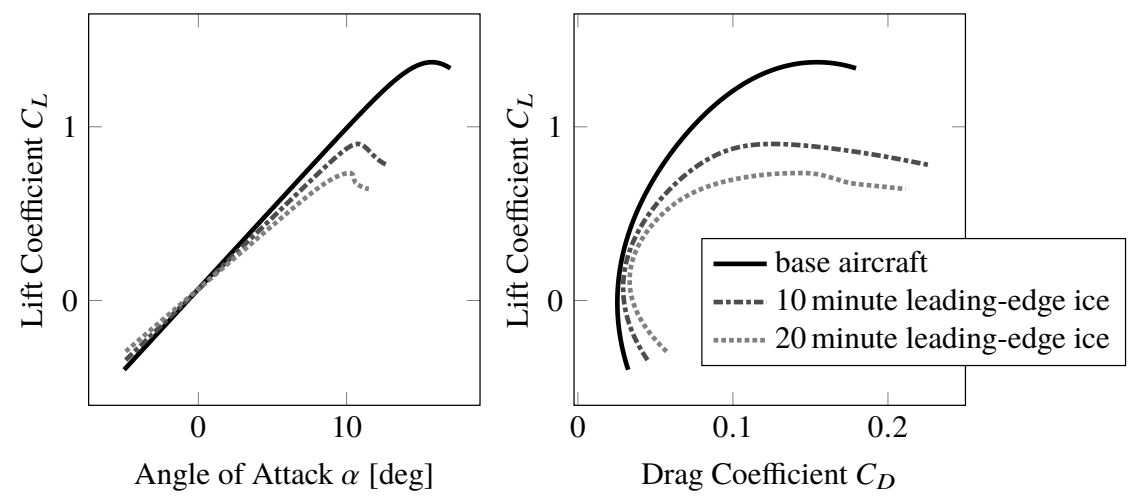

Fig. 2 Changes of lift and drag curves for different ice cases; derived aerodynamic model data for the VFW 614 ATTAS; from [16].

\section{Ice-Induced Limitations of Aircraft Flight Performance}

The main influence of icing on a fixed-wing aircraft is the limitation of its flight performance. It constrains the possible aircraft operations e.g., the aircraft's climb ability. For transport class airplanes the thrust-to-weight ratio reveals these operational limits. Therefore the required thrust-to-weight ratio $\mathrm{TWR}_{\text {req }}$ for a steady horizontal flight is analyzed and compared to the maximum available thrust-to-weight ratio $\mathrm{TWR}_{\max }$ at the given flight point:

$$
\mathrm{TWR}_{\mathrm{req}}=\frac{F_{\mathrm{E}, \mathrm{req}}}{m_{\mathrm{AC}} \cdot g}, \quad \mathrm{TWR}_{\max }=\frac{F_{\mathrm{E}, \text { max }}}{m_{\mathrm{AC}} \cdot g},
$$


where $F_{\mathrm{E}}$ denotes the engine thrust, $m_{\mathrm{AC}}$ the aircraft mass and $g$ the gravitational acceleration. The difference between the required and the maximum available thrust-to-weight ratio together with the true airspeed $V_{\mathrm{TAS}}$ determines the specific excess power SEP [37]

$$
\mathrm{SEP}=\left(\mathrm{TWR}_{\max }-\mathrm{TWR}_{\mathrm{req}}\right) \cdot V_{\mathrm{TAS}}
$$

which is equivalent to the maximum available climb rate at a given speed and altitude.

DLR's Matlab tool "MAPET" (Model based Aircraft Performance Evaluation Tool) [38] is used with both simulation models and the different available ice configurations for flight performance analysis. An analysis was performed for numerous altitudes up to $20,000 \mathrm{ft}$ and different aircraft masses and gave well comparable results in all cases. For example, the results presented herein are limited to one altitude (10,000 ft) and aircraft mass (Phenom 300: 7,500 kg; ATTAS: $19,500 \mathrm{~kg}$ ). This altitude was chosen because icing is likely to occur in the lower altitude part of the flight envelope where aircraft mainly operate during climb, descend and holding. For example, the well known accident of American Eagle flight 4184 near Roselawn, Indiana, was caused by a severe icing encounter during holding at 10,000 ft altitude [3].

Figure 3 illustrates the Phenom 300's change of thrust-to-weight ratio and specific excess power versus indicated airspeed (base aircraft and two ice configurations).Note, that the distinct information about the flight performance is proprietary. It becomes clearly visible that the aerodynamic degradation yields the expectable limitation of the aircraft's operational envelope. The required thrust-to-weight ratio in Fig. 3a significantly increases for indicated airspeeds (IAS) above $200 \mathrm{kt}$ in both ice cases. Because of the well comparable identified increase in zero-lift drag for run-back and leading-edge ice the maximum achievable airspeed is very similar for the different ice cases and also far below the base

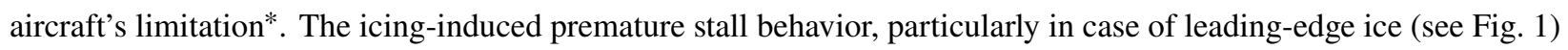
and the corresponding drag increase cause also a restriction of the minimum airspeed, which could be theoretically achieved in steady flight with the available engine thrust. But the icing-induced stall speed increase found in this analysis does not affect the normal operational envelope of the aircraft, because the aircraft is normally operated at indicated

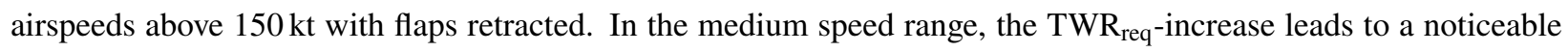
reduction of SEP in Fig. 3b] which is in accordance with the expectations from literature [4, 21, 39, 40] and reported occurrences in the past [2, 22, 23, 41].

Similar results are obtained from the evaluation of the VFW 614 ATTAS simulation model under icing influence. Figure 4 contains $\mathrm{TWR}_{\text {req }}$ and SEP versus indicated airspeed for the different ice cases. The continuous aerodynamic degradation for the increasing time of ice accumulation in Fig. 2 propagates to TWR $_{\text {req }}$ and SEP. The lower zero-lift drag increase (compared to the degradation given in Fig. 11] results in a lower maximum speed reduction for steady

\footnotetext{
*Note that the base aircraft model is not identified for high Mach numbers and therefore does not sufficiently describe the aircraft's characteristics at very high speeds. In consequence, the shown maximum achievable indicated airspeed in Fig. 3 is likely to be overpredicted. Nevertheless, this does not affect the conclusions made from the provided results.
} 


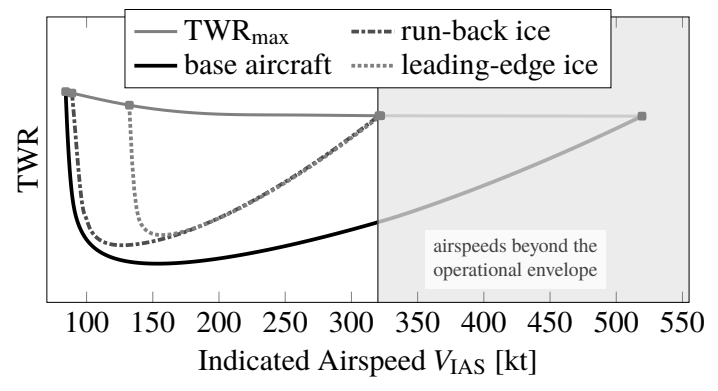

(a) Required thrust-to-weight ratio $\left(\mathrm{TWR}_{\mathrm{req}}\right)$ in comparison to maximum available TWR.

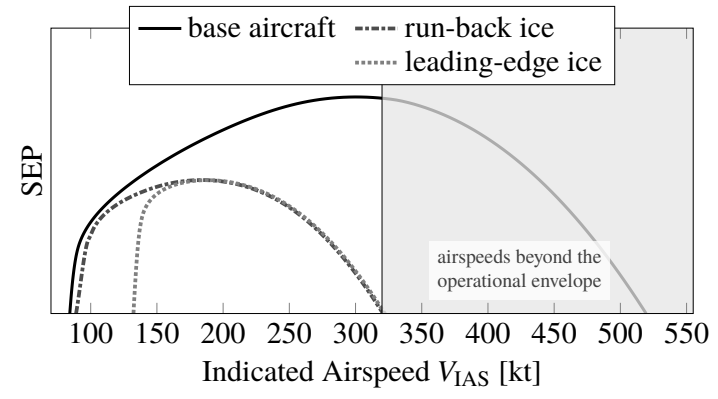

(b) Specific excess power (SEP).

Fig. 3 Limited flight performance under icing conditions on the example of required thrust-to-weight ratio and specific excess power: results for base aircraft and two different ice cases at identical altitude and aircraft mass; Phenom 300.

flight and remaining climb capabilities for both ice conditions. The lift reduction and large increase of drag for medium angles of attack leads to the limitation of minimum achievable speeds for steady flight in Fig. 4a. The specific excess power at low airspeeds (below $175 \mathrm{kt}$ IAS) is significantly restricted for leading-edge ice, especially for the 20 minute ice shape, which limits the aircraft's operational envelope.

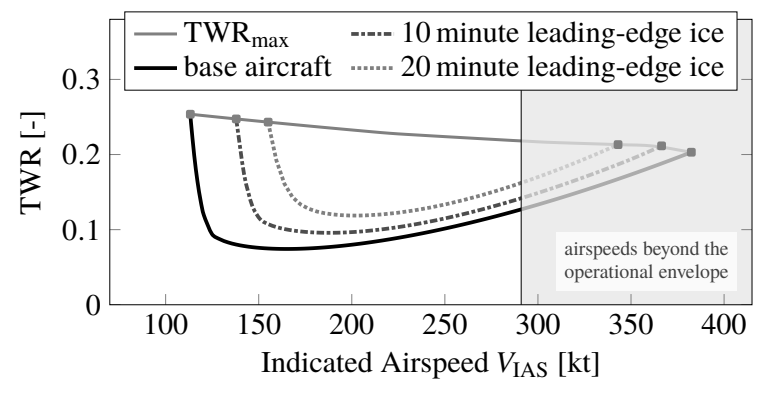

(a) Required thrust-to-weight ratio $\left(\mathrm{TWR}_{\mathrm{req}}\right)$ in comparison to maximum available TWR.

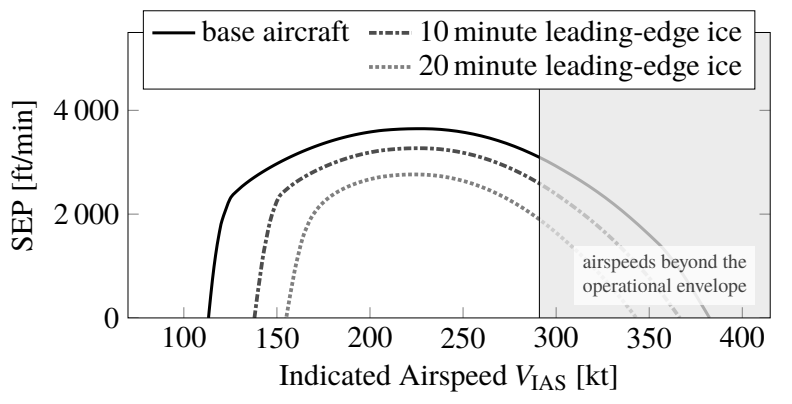

(b) Specific excess power (SEP).

Fig. 4 Illustration of limited flight performance under icing conditions on the example of thrust-to-weight ratio and specific excess power: results for base aircraft and two different ice cases at identical altitude and aircraft mass; VFW 614 ATTAS.

All in all, these results regarding the aircraft flight performance under icing influence meet the general expectations concerning the aircraft degradation. The homogeneous degrading effect of ice becomes clearly visible, but Figs. 3 and 4 also reveal for the ice shapes tested that the performance seems more sensitive to leading-edge ice than run-back ice. These results are not surprising and well known, since pilots and engineers are familiar with the phenomena of icing for decades. But nevertheless, the results are important from different points of view:

1) Due to the homogeneous and reliable model behavior concerning the flight performance degradation (in accordance with the results of previous studies, e.g., Refs. [4, 39, 40]), the confidence in a correct model 
formulation and implementation is strengthened.

2) The different forms of ice shapes on distinct aircraft cause homogeneous degradations of the aircraft flight performance. Therefore, the attempt to develop an ice detection methodology based on these changes as given in Ref. [34] seems reasonable.

3) The results allow to draw good assumptions of the expectable degradation in general, although these are only an exemplary part of the complete performance evaluation for the aircraft operational envelope. Nevertheless, an evaluation of flight performance changes due to icing effects does only make sense in the lower altitude part of the envelope (below approx. 20,000 ft), where icing conditions normally occur.

\section{Ice-Induced Changes in Flight Dynamics}

The aerodynamic degradation caused by wing ice is assumed to have an influence on the aircraft's dynamic behavior. But the distinct effects on longitudinal and especially lateral motion are dependent on the magnitude of degradation and the location of the corresponding ice shape. To compare icing-induced changes of a certain ice configuration to another and to the basic aircraft it is suitable to analyze the characteristics of the dynamic modes. Therefore, the eigenvalues of the linearized system for a steady state trim condition are evaluated.

As an example, both aircraft models (without and with icing influence) are trimmed at 10,000 ft for two different indicated airspeeds: $175 \mathrm{kt}$ and $235 \mathrm{kt}$. The airspeeds were chosen because they represent a relatively low speed case for the given altitude and correspond to a holding case which led to fatal accidents in the past (e.g., Ref. [3]). Furthermore, the intention of this study is not to evaluate the worst case scenario - very low speed and premature stall due to icing which has to be avoided in any case, but to analyze a flight condition more common in daily operations which might be more relevant for pilots. The aircraft weight and balance configurations are set to values given in Section III

Figure 5 illustrates the changes of roots in the complex plane for the Phenom 300 with run-back and leading-edge ice. Note, that the distinct numbers of the roots' locations as well as the trim conditions are proprietary. The results show in general that the qualitative influences of the ice shapes are independent of the airspeed (and altitude). For the investigated ice configurations only a slight influence on the short period characteristics is noticeable. The model identification [17] did also not reveal a strong icing effect on the aircraft's overall pitching characteristics. In contrast, the phugoid mode is significantly affected by each ice configuration in a well comparable manner. The lower right zoom-plot in Fig. 5 shows that the phugoid roots of the ice configurations move away from the base aircraft's root: the significant drag increase changes the aircraft's lift-to-drag ratio and therefore the phugoid characteristics.

The Dutch roll becomes better damped for both ice cases which can be attributed to the local drag increase on the wing and the consequent increase of yaw damping. Moreover, the rolling mode root moves away from the origin due to a higher aerodynamic damping. This increase is larger for run-back ice than for the leading-edge case and can be explained by the slightly different changes in lift characteristics for these two ice shapes. The ice cases reveal an increase 


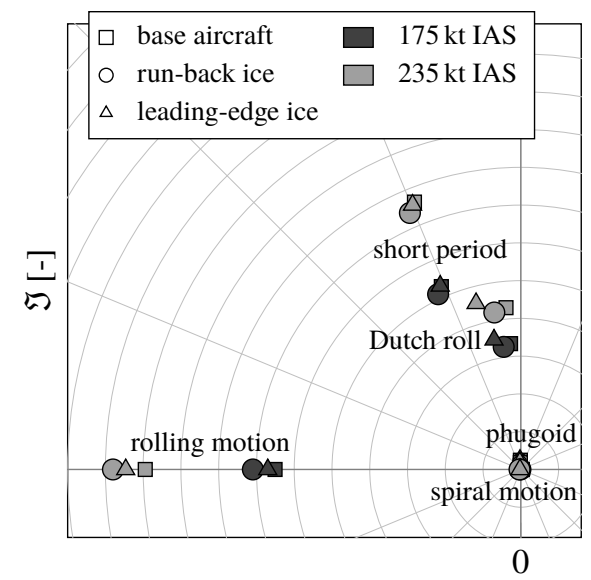

$\mathfrak{R}[-]$

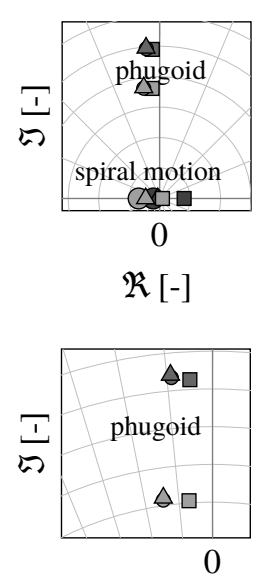

$\mathfrak{R}[-]$

Fig. 5 Ice-induced changes of aircraft dynamics: exemplary locations of roots in complex plane for the Phenom 300 model with and without icing.

of lift curve slope at distinct angles of attack - compared to the base aircraft (see Fig. 1) - which results in an increase of roll damping for a given local angle of attack change. Furthermore, both ice shape configurations cause the aircraft's spiral mode to stabilize (see upper-right zoom-plot in Fig. [5]. The spiral mode is stable [42] if

$$
N_{r} L_{\beta}-N_{\beta} L_{r}>0 .
$$

In the present case of ice analysis the yaw damping $N_{r}$ is increased due to the local drag increase on the wing. Moreover, the dihedral effect $L_{\beta}$ is enhanced due to the reduced sensitivity of the aircraft's local lift to a local angle of attack change which consequently results in a reduced rolling moment/motion.

The evaluation of the ATTAS' dynamic modes reveals a different picture of the ice-induced changes. Figure 6 contains the root locations in the complex plane for the example flight point in $10,000 \mathrm{ft}$. The corresponding trim conditions are given in Table 1 As a consequence of the lift degradation (see Fig. 2) the necessary angle of attack to obtain a horizontal steady-state flight is increased with the icing severity. The increase of ice accumulation time between the different leading-edge ice shapes leads to a homogeneous change of dynamic mode characteristics from base aircraft over the 10 minute case to the 20 minute configuration. This further ensures the confidence in the model concerning a reliable implementation of the ice degradation. The drag increase causes a higher damping of the phugoid mode, whereas the short period's damping and natural frequency are reduced with growing leading-edge ice accumulation. Moreover, only a minor influence of both ice shapes on the Dutch roll is found. The combination of local wing lift and drag changes results in new roll and yaw characteristics which seem to cancel each other. The root of the rolling mode moves under icing influence towards the origin, indicating a reduced aerodynamic damping of the rolling motion, which is a direct result of the ice-induced decrease of the local wing lift curve slope (in accordance with the change of 

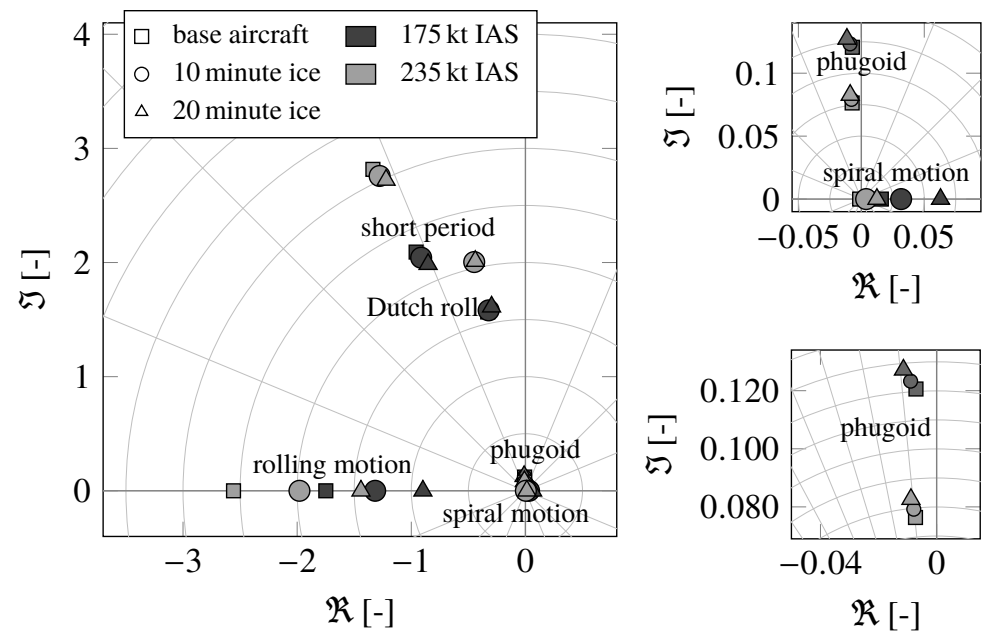

Fig. 6 Ice-induced changes of aircraft dynamics: exemplary locations of roots in complex plane for VFW 614 ATTAS model with and without icing.

the complete aircraft aerodynamic characteristics in Fig. 2). The spiral mode is significantly destabilized under the influence of leading-edge ice. Particularly the 20 minute ice shape causes a significant change of the corresponding root location on the right side of the complex plane. The spiral mode stability criterion in Equation (3) indicates that the mode's stability is directly affected by the aircraft's roll-yaw coupling, which in turn is a result of the local icing-induced aerodynamic degradation (lift/drag). As mentioned before, the ice shapes show a strong influence on the ATTAS roll characteristics and therefore also destabilize the spiral mode.

Table 1 Trim conditions for horizontal steady-state flight with different ice shapes; VFW 614 ATTAS.

\begin{tabular}{lccc}
\hline \multirow{2}{*}{ Airspeed } & & \multicolumn{2}{c}{ Angle of Attack } \\
& base & $\begin{array}{c}10 \text { minute } \\
\text { leading-edge ice }\end{array}$ & $\begin{array}{c}\text { 20 minute } \\
\text { leading-edge ice }\end{array}$ \\
\hline $175 \mathrm{kt} \mathrm{IAS}$ & $5.76 \mathrm{deg}$ & $6.51 \mathrm{deg}$ & $7.41 \mathrm{deg}$ \\
$235 \mathrm{kt} \mathrm{IAS}$ & $2.61 \mathrm{deg}$ & $2.94 \mathrm{deg}$ & $3.28 \mathrm{deg}$ \\
\hline
\end{tabular}

\section{A. Comparison of Changes}

The investigated cases show different results concerning the icing influence on the aircraft flight dynamics but similar results for both airspeeds. Table 2 contains a comparison of the change of several aircraft characteristics. Only the phugoid, represented through its damping $\zeta_{\mathrm{PH}}$, shows a well comparable behavior under the different icing influences for both aircraft. The corresponding strong damping increase is a direct result of the additional drag respectively reduced lift-to-drag ratio. The effect on the short-period damping $\zeta_{\mathrm{SP}}$ is different for both aircraft and the change of natural frequency $\omega_{0, \mathrm{SP}}$ does also not show homogeneous results: the effect for the leading-edge ice case on the Phenom 300 differs from the other changes in $\omega_{0, \mathrm{SP}}$. 
Table 2 Comparison of relative change of aircraft dynamic motion: Phenom 300 and VFW 614 ATTAS results for different ice configurations ( $\Uparrow$ strong increase, $\uparrow$ increase, $\downarrow$ decrease); no detectable influence of airspeed on the results.

\begin{tabular}{llcccc}
\hline & & \multicolumn{2}{c}{ Phenom 300 } & \multicolumn{2}{c}{ VFW 614 ATTAS } \\
dynamic mode & & run-back ice & leading-edge ice & $\begin{array}{c}\text { 10 minute } \\
\text { leading-edge ice }\end{array}$ & $\begin{array}{c}\text { 20 minute } \\
\text { leading-edge ice }\end{array}$ \\
\hline phugoid & $\zeta_{\mathrm{PH}}$ & $\Uparrow$ & $\Uparrow$ & $\Uparrow$ & $\Uparrow$ \\
\multirow{2}{*}{ short period } & $\zeta_{\mathrm{SP}}$ & $\uparrow$ & $\uparrow$ & $\downarrow$ & $\downarrow$ \\
& $\omega_{0, \mathrm{SP}}$ & $\downarrow$ & $\uparrow$ & $\downarrow$ & $\downarrow$ \\
Dutch roll & $\zeta_{\mathrm{DR}}$ & $\Uparrow$ & $\Uparrow$ & $\downarrow$ & $\downarrow$ \\
rolling motion & $\omega_{0, \mathrm{DR}}$ & $\downarrow$ & $\uparrow$ & $\uparrow$ & $\uparrow$ \\
spiral motion & $T_{\mathrm{RO}}$ & $\downarrow$ & $\downarrow$ & $\Uparrow$ & $\Uparrow$ \\
\hline
\end{tabular}

Moreover, the change of Dutch roll characteristics is completely different for the Phenom 300 and the VFW 614 ATTAS. The damping $\zeta_{\text {DR }}$ of this mode is significantly increased for both investigated ice shapes on the Phenom 300, whereas it is decreased in case of the VFW 614 ATTAS. The corresponding natural frequencies $\omega_{0, \mathrm{DR}}$ are increased except for the Phenom 300's run-back ice case, for which a slight decrease was found. The roll mode characteristics change differently for both aircraft due to the distinct aerodynamic degradation (as discussed above). Moreover, the specific influence of aerodynamic degradation on the aircraft dynamics becomes also visible in the spiral mode change, which is stabilized for the Phenom 300 under icing influence and destabilized for the VFW 614 ATTAS.

All in all, the evaluation results reveal that the icing-induced changes of aircraft dynamics strongly depend on the distinct aerodynamic degradation and the base aircraft's characteristics itself. Therefore, it is not possible to formulate a generally valid statement about the change of aircraft dynamics under icing influence herein. Hence, it could also not be verified that existing methods to detect icing based on a changed aircraft dynamic behavior (e.g., [27, 29, 43, 44]) could be reliably used.

\section{B. Influence on Handling Qualities}

The change of aircraft dynamics under icing influence could lead to an alteration of handling qualities. Several numerical criteria given in "MIL-STD-1797A" [45] are directly based on the aircraft's mode characteristics (damping, natural frequency, time constant). Therefore, the evaluation of these criteria delivers a first but limited impression of the icing influence on handling qualities focusing only on open-loop aircraft control. Both aircraft can be categorized as class II (light or medium transport) and the handling qualities are evaluated for category B and C operations. This handling qualities evaluation is done for an airspeed of $175 \mathrm{kt}$ at $10,000 \mathrm{ft}$ altitude.

The evaluation reveals that the ice-induced changes of aircraft aerodynamics do not worsen or significantly affect 
both aircraft's handling qualities. One has to keep in mind that the evaluation was intentionally done for flight conditions without significant flow separation, which could lead to a deterioration of handling qualities. But again, the analysis' purpose was to investigate a case similar to normal operational flight conditions. Table 3 provides an overview of the resulting handling qualities assessment based on the analyzed numerical criteria for the eigenvalues of the linearized dynamic system. In detail:

The damping of the Phenom 300's phugoid mode is increased for both icing conditions due to the higher drag: level 1 handling qualities are not affected. The short-period damping shows no significant change under ice influence and consequently the level 1 rating persists. The increased damping of the Dutch roll for each ice case (with the natural frequency remaining nearly constant) results in level 1 handling qualities and even enlarges the distance to the level 2 boundary. Because of ice showing only a minor influence on the rolling motion, the handling qualities criterion based on the time constant $T_{\mathrm{RO}}$ does not encounter any significant changes. One major effect on the dynamic motion of the Phenom 300 is the stabilized spiral motion. Therefore the corresponding handling qualities criterion based on the time to double is not applied and the assessment results in level 1.

Partly similar results are obtained for the handling qualities assessment of the VFW 614 ATTAS with different ice shapes. Except for the ATTAS' spiral mode with 20 minute leading-edge ice, the level 1 handling qualities are maintained. The phugoid, short-period and Dutch roll modes are varied only slightly, which results in handling qualities well comparable to the base aircraft. The change of roll characteristics with growing ice shapes does not affect the level 1 rating, but the assessment moves towards level 2. The resulting destabilizing effect of wing ice on the spiral mode slightly worsens the handling qualities: for the 10 minute leading-edge ice level 1 ratings could still be achieved but the 20 minute ice shape leads to a level 2 assessment.

Table 3 Comparison of handling qualities based on numerical criteria (class II, categories B \& C) for one example flight condition (175 kt IAS, 10,000 ft altitude): results of Phenom 300 and VFW 614 ATTAS with different ice configurations; base aircraft are Level 1 for all criteria.

\begin{tabular}{lcccc}
\hline & \multicolumn{2}{c}{ Phenom 300 } & \multicolumn{2}{c}{ VFW 614 ATTAS } \\
numerical criterion & run-back ice & leading-edge ice & $\begin{array}{c}\text { 10 minute } \\
\text { leading-edge ice }\end{array}$ & $\begin{array}{c}\text { 20 minute } \\
\text { leading-edge ice }\end{array}$ \\
\hline \hline phugoid damping & Level 1 & Level 1 & Level 1 & Level 1 \\
short period damping & Level 1 & Level 1 & Level 1 & Level 1 \\
$\begin{array}{l}\text { Dutch roll damping } \\
\text { natural frequency }\end{array}$ & Level 1 & Level 1 & Level 1 & Level 1 \\
rolling motion time constant & Level 1 & Level 1 & Level 1 & Level 1 \\
spiral motion time to double & (Level 1) & (Level 1) & Level 1 & Level 2 \\
\hline
\end{tabular}




\section{Conclusion}

The influence of icing on aircraft characteristics was analyzed. An evaluation of the variation of aircraft performance and dynamics was conducted based on simulation models for two different aircraft types and two distinct ice configurations in each case. A homogeneous icing-induced degradation of flight performance parameters was found, whereas the changes of flight dynamics are case-dependent. Within this work no general conclusions on the effects on aircraft dynamics can be drawn for the following reasons: the number of combinations of aircraft and distinct ice configurations is limited in this study and the results are inconclusive; the changes of the aircraft's dynamic modes are a direct, reasonable effect of the change of local aircraft aerodynamics which is different for different ice configurations. Therefore, it is not clear if any general conclusions on the change aircraft dynamics could be made at all. These results are in contrast but also complementary to existing work, which showed different results based on different ice cases for different aircraft or certain model assumptions. Nevertheless, the icing-related strong increase of drag and its further consequences could be found in aircraft performance and dynamic characteristics. Moreover, the exemplary evaluation of numerical handling qualities changes for the investigated flight conditions did not show any significant deterioration.

The high-quality simulation models used for this evaluation are contributing to the general understanding of the icing influence on aircraft characteristics. Nevertheless, further information containing distinct ice configurations on different aircraft would be beneficial for future work.

\section{References}

[1] Green, S. D., “A Study of U. S. Inflight Icing Accidents and Incidents, 1978 to 2002,” 44th AIAA Aerospace Sciences Meeting and Exhibit, American Institute of Aeronautics and Astronautics, Inc. (AIAA), Reno, Nevada, USA, 2006. doi:10.2514/6.2006-82.

[2] Anon., Final Report (BFU 5X011-0/98), German Federal Bureau of Aircraft Accident Investigation, Braunschweig, Germany, April 2001.

[3] Anon., Aircraft Accident Report (NTSB/AAR-96/01, DCA95MA001), Safety Board Report, National Transportation Safety Board (NTSB), Washington, DC, USA, July 9th 1996.

[4] Anon., "Ice Accretion Simulation," AGARD Advisory Report 344, Advisory Group for Aerospace Research \& Development (AGARD) - Fluid Dynamics Panel Working Group 20, North Atlantic Treaty Organization (NATO), Neuilly-Sur-Seine, France, December 1997.

[5] Gray, V. H., "Prediction of aerodynamic penalties caused by ice formations on various airfoils," Technical Note D-2166, National Aeronautics and Space Administration (NASA), Washington, D.C., USA, February 1964.

[6] Bragg, M. B., Broeren, A. P., and Blumenthal, L. A., "Iced-airfoil aerodynamics," Progress in Aerospace Sciences, Vol. 41, No. 5, 2005, pp. 323-362. doi:10.1016/j.paerosci.2005.07.001, URL https://doi.org/10.1016/j.paerosci.2005.07.001 
[7] Broeren, A. P., Bragg, M. B., Addy Jr., H. E., Lee, S., Moens, F., and Guffond, D., "Effect of High-Fidelity Ice-Accretion Simulations on Full-Scale Airfoil Performance," Journal of Aircraft, Vol. 47, No. 1, 2010, pp. 240-254. doi:10.2514/1.45203.

[8] Broeren, A. P., Whalen, E. A., Busch, G. T., and Bragg, M. B., “Aerodynamic Simulation of Runback Ice Accretion,” Journal of Aircraft, Vol. 47, No. 3, 2010, pp. 924-939. doi:10.2514/1.46475.

[9] Broeren, A. P., Addy Jr., H. E., Monastero, M. C., and McClain, S. T., “Three-Dimensional Ice-Accretion Measurement Methodology for Experimental Aerodynamic Simulation,” Journal of Aircraft, Vol. 55, No. 2, 2018, pp. 817-828. doi: 10.2514/1.C034580.

[10] Ranuado, R. J., Batterson, J. G., Reehorst, A. L., Bond, T., and O’Mara, T. M., "Determination of Longitudinal Aerodynamic Derivatives Using Flight Data from an Icing Research Aircraft,” 27th AIAA Aerospace Sciences Meeting, American Institute of Aeronautics and Astronautics, Inc. (AIAA), Reno, Nevada, USA, 1989. doi:10.2514/6.1989-754.

[11] Ratvasky, T. P., and Ranuado, R. J., "Icing Effects on Aircraft Stability and Control Determined from Flight Data. Preliminary Results," 31st AIAA Aerospace Sciences Meeting and Exhibit, American Institute of Aeronautics and Astronautics, Inc. (AIAA), Reno, Nevada, USA, 1993. doi:10.2514/6.1993-398.

[12] Lee, S., Barnhart, B. P., and Ratvasky, T. P., "Dynamic Wind-Tunnel Testing of a Sub-Scale Iced S-3B Viking," AIAA Atmospheric and Space Environments Conference, American Institute of Aeronautics and Astronautics, Inc. (AIAA), Toronto, Ontario, Canada, 2010. doi:10.2514/6.2010-7986.

[13] Gingras, D. R., "Requirements and Modeling of In-flight Icing Effects for Flight Training," AIAA Modeling and Simulation Technologies (MST) Conference, American Institute of Aeronautics and Astronautics, Inc. (AIAA), Boston, Massachusetts, USA, 2013. doi:10.2514/6.2013-5075.

[14] Son, C., and Yee, K., "Procedure for Determining Operation Limits of High-Altitude Long-Endurance Aircraft Under Icing Conditions," Journal of Aircraft, Vol. 55, No. 1, 2018, pp. 294-309. doi:10.2514/1.C034490.

[15] Deiler, C., “Time Domain Output Error System Identification of Iced Aircraft Aerodynamics," CEAS Aeronautical Journal, Vol. 8, No. 2, 2017, pp. 231-244. doi:10.1007/s13272-016-0231-2.

[16] Deiler, C., and Kilian, T., "Dynamic Aircraft Simulation Model Covering Local Icing Effects," CEAS Aeronautical Journal, Vol. 9, No. 3, 2018, pp. 429-444. doi:10.1007/s13272-018-0291-6.

[17] Deiler, C., "Aerodynamic Modeling, System Identification, and Analysis of Iced Aircraft Configurations," Journal of Aircraft, Vol. 55, No. 1, 2018, pp. 145-161. doi:10.2514/1.C034390.

[18] Bragg, M. B., Hutchison, T., Merret, J., Oltman, R., and Pokhariyal, D., "Effect of Ice Accretion on Aircraft Flight Dynamics," 38th AIAA Aerospace Sciences Meeting and Exhibit, American Institute of Aeronautics and Astronautics, Inc. (AIAA), Reno, Nevada, USA, 2000. doi:10.2514/6.2000-360. 
[19] Brown, A. P., "Negative Speed Stability, a Factor in Transport Airplane Icing Upsets," 20th AIAA Applied Aerodynamics Conference, American Institute of Aeronautics and Astronautics, Inc. (AIAA), St. Louis, Missouri, USA, 2002. $10.2514 / 6.2002-3051$.

[20] Deters, R. W., Dimock, G. A., and Selig, M. S., "Icing Encounter Flight Simulator," Journal of Aircraft, Vol. 43, No. 5, 2006, pp. 1528-1537. doi:10.2514/1.20364.

[21] Lampton, A., and Valasek, J., "Prediction of Icing Effects on the Dynamic Response of Light Airplanes," Journal of Guidance, Control, and Dynamics, Vol. 30, No. 3, 2007, pp. 722-732. doi:10.2514/1.25687.

[22] Anon., Report On Serious Incident (AIBN/Rep. 2009/02), Accident Investigation Board Norway (AIBN), Lillestrøm, Norway, January 2009.

[23] Anon., Aircraft Incident Report (EW/G2014/10/04), AAIB Bulletin: 9/2015, Air Accidents Investigation Branch (AAIB), Department of Transport, Farnborough, UK, September 2015.

[24] Anon., Aircraft Accident Report (EW/G2016/12/08), AAIB Bulletin: 12/2017, Air Accidents Investigation Branch (AAIB), Department of Transport, Farnborough, UK, December 2017. URLhttps://www . gov.uk/aaib-reports/aaib-investigationto-atr-72-212-a-500-version-g-cobo

[25] Nabi, H. N., Lombaerts, T., Zhang, Y., van Kampen, E., Chu, Q. P., and de Visser, C. C., "Effects of Structural Failure on the Safe Flight Envelope of Aircraft," Journal of Guidance, Control, and Dynamics, Vol. 41, No. 6, 2018, pp. 1257-1275. doi:10.2514/1.G003184.

[26] Bragg, M. B., Perkins, W. R., Sarter, N. B., Başar, T., Voulgaris, P. G., Gurbacki, H. M., Melody, J. W., and McCray, S. A., “An Interdisciplinary Approach to Inflight Aircraft Icing Safety," 36th AIAA Aerospace Sciences Meeting and Exhibit, American Institute of Aeronautics and Astronautics, Inc. (AIAA), Reno, Nevada, USA, 1998. doi:10.2514/6.1998-95.

[27] Myers, T. T., Klyde, D. H., and Magdaleno, R. E., “The Dynamic Icing Detection System (DIDS)," 38th AIAA Aerospace Sciences Meeting and Exhibit, American Institute of Aeronautics and Astronautics, Inc. (AIAA), Reno, Nevada, USA, 1999. doi: $10.2514 / 6.2000-364$.

[28] Melody, J. W., Başar, T., Perkins, W. R., and Voulgaris, P. G., "Parameter Identification for Inflight Detection and Characterization of Aircraft Icing," Control Engineering Practice, Vol. 8, No. 9, 2000, pp. 985-1001. doi:10.1016/S0967-0661(00)00046-0.

[29] Bragg, M. B., Başar, T., Perkins, W. R., Selig, M. S., Voulgaris, P. G., Melody, J. W., and Sater, N. B., "Smart icing systems for aircraft icing safety," 40th AIAA Aerospace Sciences Meeting and Exhibit, American Institute of Aeronautics and Astronautics, Inc. (AIAA), Reno, Nevada, USA, 2002. doi:10.2514/6.2002-813.

[30] Aykan, R., Hajiyev, C., and Caliskan, F., "Aircraft Icing Detection, Identification and Reconfigurable Control Based on Kalman Filtering and Neural Networks," AIAA Atmospheric Flight Mechanics Conference and Exhibit, American Institute of Aeronautics and Astronautics, Inc. (AIAA), San Francisco, California, USA, 2005. doi:10.2514/6.2005-6220. 
[31] Gingras, D. R., Barnhart, B. P., Ranuado, R. J., Ratvasky, T. P., and Morelli, E. A., "Envelope Protection for In-Flight Ice Contamination,” 47th Aerospace Sciences Meeting, American Institute of Aeronautics and Astronautics, Inc. (AIAA), Orlando, Florida, USA, 2009. doi:10.2514/6.2009-1458.

[32] Dong, Y., and Ai, J., "Research on inflight parameter identification and icing location detection of the aircraft," Aerospace Science and Technology, Vol. 29, No. 1, 2013, pp. 305 - 312. doi:10.1016/j.ast.2013.03.012.

[33] Petit, G., "Method and Device for Detecting Degradation of Performance of an Aircraft,", 2005. URL https://www . google. com/patents/US20050288895. US Patent 2005/0288895 A1.

[34] Deiler, C., and Fezans, N., "Performance-Based Ice Detection Methodology," Atmospheric Flight Mechanics Conference, AIAA Aviation Forum and Exhibition, American Institute of Aeronautics and Astronautics, Inc. (AIAA), Denver, Colorado, USA, 2017. doi:10.2514/6.2017-3394.

[35] Deiler, C., Ohme, P., Raab, C., Braga de Mendonca, C., and da Silva, D. M., "Facing the Challenges of Supercooled Large Droplet Icing: Results of a Flight Test Based Joint DLR-Embraer Research Project,” International Conference on Icing of Aircraft, Engines, and Structures, SAE International, Minneapolis, MN, USA, 2019. doi:10.4271/2019-01-1988, URL https://saemobilus.sae.org/content/2019-01-1988/

[36] Fischenberg, D., “A Method to Validate Wake Vortex Encounter Models from Flight Test Data," 27th International Congress of the Aeronautical Sciences, International Council of the Aeronautical Sciences (ICAS), Nice, France, 2010. URL http://www.icas.org/ICAS_ARCHIVE/ICAS2010/PAPERS/041.PDF

[37] Phillips, W. F., Mechanics of Flight, John Wiley \& Sons, Inc., Hoboken, New Jersey, USA, 2004.

[38] Ohme, P., and Raab, C., "A Model-Based Approach to Aircraft Performance Assessment," AIAA Atmospheric Flight Mechanics Conference and Exhibit, American Institute of Aeronautics and Astronautics, Inc. (AIAA), Honolulu, Hawaii, USA, 2008. doi: $10.2514 / 6.2008-6873$.

[39] Ranaudo, R. J., Mikkelsen, K. L., McKnight, R. C., and Perkins, P. J. J., "Performance Degradation of a Typical Twin Engine Commuter Type Aircraft in Measured Natural Icing Conditions," 22nd AlAA Aerospace Sciences Meeting, American Institute of Aeronautics and Astronautics, Inc. (AIAA), Reno, Nevada, USA, 1984. doi:10.2514/6.1984-179.

[40] Whalen, E. A., Lee, S., Bragg, M. B., and Ratvasky, T. P., "Characterizing the Effect of Ice on Aircraft Performance and Control from Flight Data," 40th AIAA Aerospace Sciences Meetings and Exhibit, American Institute of Aeronautics and Astronautics, Inc. (AIAA), Reno, Nevada, USA, 2002.

[41] Anon., Accident Report (BFU EX001-0/00), German Federal Bureau of Aircraft Accident Investigation, Braunschweig, Germany, October 2002, in German.

[42] Yechout, T. R., Introduction to Aircraft Flight Mechanics, $2^{\text {nd }}$ ed., American Institute of Aeronautics and Astronautics, Inc., 1801 Alexander Bell Drive, Reston, Virgina, USA, 2014. 
[43] Melody, J. W., Hillbrand, T., Başar, T., and Perkins, W. R., "Hळ Parameter Identification for Inflight Detection of Aircraft Icing: The Time-Varying Case," Control Engineering Practice, Vol. 9, No. 12, 2001, pp. 1327-1335. doi:10.1016/S09670661(01)00081-8.

[44] Gingras, D. R., Barnhart, B. P., Ranuado, R. J., Martos, B., Ratvasky, T. P., and Morelli, E. A., "Development and Implementation of a Model-Driven Envelope Protection System for In-Flight Ice Contamination,” AIAA Guidance, Navigation and Control Conference, American Institute of Aeronautics and Astronautics, Inc. (AIAA), Toronto, Ontario, Canada, 2010. doi:10.2514/6.2010-8141.

[45] U. S. Department of Defense, "MIL-STD-1797 A: Military Standard: Flying Qualities of Piloted Aircraft,”, January 1990. 